\title{
Patient loyalty to HIV care in an HIV facility in Eldoret, Kenya:
}

\section{A mediated mediation [version 1; peer review: 2 approved}

\section{with reservations]}

\author{
Felishana Cherop (D1, Michael Korir¹, Vincent Bagire², Juddy Wachira ${ }^{3}$ \\ ${ }^{1}$ Department of Management Sciences and Entrepreneurship, School of Business and Economics, Moi University, Eldoret, 30100, \\ Kenya \\ ${ }^{2}$ Department of Business Administration, Makerere University Business School (MUBS), Kampala, Uganda \\ ${ }^{3}$ Department of Behavioural Sciences, School of Medicine, Moi University, Eldoret, 30100, Kenya
}

V1 First published: 14 Sep 2020, 3:48

https://doi.org/10.12688/aasopenres.13121.1

Latest published: 22 Dec 2022, 3:48

https://doi.org/10.12688/aasopenres.13121.2

\begin{abstract}
Patient loyalty is the continuous commitment and engagement in care where patients can improve and sustain quality of life through continuous use of medical care. Identifying strengths and weaknesses in providing excellent quality care is a key measure of success of healthcare professionals and hospital management. However, few studies have examined patient loyalty from a strategic leadership perspective within HIV health care systems. The purpose of this study is to determine how patient loyalty to HIV care is influenced by multiple factors in a healthcare system environment. The study employs a mixed-methods approach guided by the complexity theory and the theory of planned behavior. A total of 444 surveys with (50 healthcare providers and 394 adult HIV-infected patients) currently on antiretroviral drugs, as well as 22 in-depth interviews with healthcare providers will be conducted. The study will be done at AMPATH Eldoret Kenya. We will use stratified proportionate and census sampling methods to select study participants for the survey while purposive and convenient sampling techniques will be used for indepth interviews. Structured questionnaires and interviewer guides will guide data collection. Quantitative data analysis will entail hierarchical regression to test direct effects while multiple regression will test the mediation effects using the Hayes PROCESS Model No.6 in SPSS. Qualitative data analysis will be conducted using a thematic analytical method.
\end{abstract}

Keywords

Strategic leadership, Healthcare system factors, Relational Dynamics, Patient loyalty

\section{Open Peer Review}

Approval Status ? ?

1 2

version 2

(revision)

22 Dec 2022

version 1

14 Sep 2020

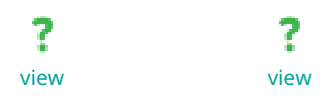

1. Selim Ahmed ID, World School of Business, World University of Bangladesh, Dhaka, Bangladesh

2. Christel Protière (D), Aix Marseille

University, Marseille, France

Any reports and responses or comments on the article can be found at the end of the article. 
Corresponding author: Felishana Cherop (fcherop@gmail.com)

Author roles: Cherop F: Conceptualization, Methodology, Writing - Original Draft Preparation, Writing - Review \& Editing; Korir M: Conceptualization, Methodology, Supervision, Writing - Review \& Editing; Bagire V: Conceptualization, Methodology, Writing - Review \& Editing; Wachira J: Conceptualization, Methodology, Supervision, Writing - Review \& Editing

Competing interests: No competing interests were disclosed.

Grant information: This research is supported by the Consortium for Advanced Research Training in Africa (CARTA). CARTA is jointly led by the African Population and Health Research Center and the University of the Witwatersrand and funded by the Carnegie Corporation of New York (Grant No--B 8606.R02), Sida (Grant No:54100113), the DELTAS Africa Initiative (Grant No: 107768) and Deutscher Akademischer Austauschdienst (DAAD). The DELTAS Africa Initiative is an independent funding scheme of the African Academy of Sciences (AAS)'s Alliance for Accelerating Excellence in Science in Africa (AESA) and supported by the New Partnership for Africa's Development Planning and Coordinating Agency (NEPAD Agency) with funding from the Wellcome Trust (UK) and the UK government. The statements made and views expressed are solely the responsibility of the authors.

The funders had no role in study design, data collection and analysis, decision to publish, or preparation of the manuscript.

Copyright: (c) 2020 Cherop F et al. This is an open access article distributed under the terms of the Creative Commons Attribution License , which permits unrestricted use, distribution, and reproduction in any medium, provided the original work is properly cited.

How to cite this article: Cherop F, Korir M, Bagire V and Wachira J. Patient loyalty to HIV care in an HIV facility in Eldoret, Kenya: A mediated mediation [version 1; peer review: 2 approved with reservations] AAS Open Research 2020, 3:48

https://doi.org/10.12688/aasopenres.13121.1

First published: 14 Sep 2020, 3:48 https://doi.org/10.12688/aasopenres.13121.1 


\section{Introduction}

Patient loyalty is a behavioral impulse that makes a customer engage with and repeatedly purchase a particular good or service for a long time, despite situational influences having the potential to cause customer switching behavior (Adhi Mahendrayana Putu et al., 2018; Mortazavi et al., 2009; Ngurah et al., 2018). It highlights the importance of both attitude (commitment) and behavior (repeat purchasing of services) aspects of loyalty (Roberge et al., 2001). Consistent with healthcare studies specific to HIV, loyalty implies retention in care, where HIV patients are continuously engaged in care regardless of whether the care is received from a different clinic to the one in which they were originally enrolled, and when patients return to the same clinic at a particular point in time (Kiplagat et al., 2018; van der Kop et al., 2018). In Kenya, like in other countries, most studies on patient loyalty focus on the antecedents, including satisfaction, quality, hospital brand image and trust, because it increases treatment effectiveness and intentions to revisit (Agyei et al., 2014; Kim et al., 2017; Kipkirong Tarus \& Rabach, 2013; Zhou et al., 2017); however, there is a literature gap on how patient loyalty to HIV care is influenced by these antecedents. Little is known on the role of multiple factors within the healthcare system environment on patient loyalty to HIV care.

Most studies that have discussed the importance of healthcare system leadership (Gilson \& Agyepong, 2018; Gilson \& Daire, 2011) describe the role of a clinical leader (Daly et al., 2014) as demonstrating clinical knowledge and establishing a good atmosphere for collaboration (Larsson \& Sahlsten, 2016), which has the potential of determining whether patients remain loyal in care. The adaptive leadership framework (Heifetz et al., 2009) explains the importance of leadership within healthcare organizations, particularly in helping people to adapt and transcend challenging situations such as chronic diseases. However, there have been insufficient investigations to establish the role of leadership at the point of care where the interaction and relationships between patients and healthcare providers take place (Bailey et al., 2012), where a clinical leader plays a critical role in working with other providers (Edmonstone, 2011). Furthermore, clinical leadership studies emphasize on individual leaders at senior levels, overlooking those at the middle levels who deliver health care in practice in a way affected by their health care context (Nzinga, et al., 2018). Moreover, a comparative qualitative study in Kenya and Indonesia revealed challenges in ensuring good governance for health (McCollum et al., 2018), while an evaluation of the Kenyan health system established a requirement to improve healthcare systems and institutions, specifically at the county level, since they have reported challenges like unclear homogeneous management structures, insufficient capacity to develop health laws that can incorporate the civil society in the process of decision making (Mulaki \& Muchiria, 2019). Similarly, a weak leadership framework influenced healthcare delivery in South Africa (Govender et al., 2018). This creates a gap in how clinical leaders utilize strategic attributes at the operational level, to influence healthcare system performance, provider-patient relationships, and loyalty in an HIV care facility in Eldoret Kenya.

Studies on various health system building blocks indicate that health system factors such as distance to the facility, patient waiting time, used means of transport, perceived quality of service and attitude of a healthcare provider were statistically significant predictors of the number of antenatal visits in Kisumu county, Kenya (Kilowua \& Otieno, 2019). Similarly, a Kenyan qualitative study found healthcare system factors constrain HIV care providers in delivering highquality care to HIV patients (Genberg et al., 2019) while in Zambia, like in Pakistan, both health system hardware and software factors such as infrastructure to protect privacy, inflexibility in visit schedules influence patient disengagement among lost to follow up (LTFU) patients (Fatima et al., 2018; Mwamba et al., 2018). Whereas this is evident, little is known about how the healthcare system factors mediate the relationship between strategic clinical leader attributes and patient loyalty to HIV care in an HIV facility in Eldoret, Kenya. Previous studies demonstrate that manager transformational leadership influences patient-nurse relationships and patient outcomes independently of supportive practice environment particularly on patient falls with statistically significant effects, but the study did not capture clinical outcomes which could have provided a clear picture of other patient outcomes (Higgins, 2015). Besides, organizational climate mediates the relationship between transformational leadership and patient safety in Saudi hospitals (Alotaibi et al., 2015), while the hospital environment was a significant mediating factor in the relationship between empathy, assurance, and customer loyalty in the Yemeni capital (Hamood \& Alshehari, 2018). Besides, the quality of the healthcare healing environment mediated the relationship between patient satisfaction and core health delivery in Ghana. This implies that the better the healthcare environment, the more the patients are satisfied with the delivery of care (Amankwah et al., 2019).

As leadership plays a critical role in ensuring healthy relationships between patients and providers within a healthcare system (Stevenson et al., 2019), there is a need for strategies to effectively help providers, patients, and families develop and manage relationships in clinical encounters; however, the changes health care systems require to support providers as adaptive leaders must be elucidated (Anderson et al., 2015). Relational dynamics can attract and retain patients to an organization through friendship and partnership (Sexton \& Sen, 2018), and HIV is a condition that requires intermittence of patience to care, a unique relationship with service providers with understanding, tolerance and continuous assessment (Bucciardini et al., 2015). In most cases, patients lose loyalty when an ongoing relationship with primary doctors and personal trust is lost due to sharing and use of patient clinical information by others (Waibel et al., 2018), providerpatient relationships structural factors (Wachira et al., 2018) that can predict negative patient outcomes including patient 
dissatisfaction and late presentation to care (Alipoor et al., 2017; Kawonga et al., 2016; Kiplagat et al., 2018). However, there is insufficient literature on how patient-provider relational dynamics directly and indirectly mediate patient loyaltyleadership relationships in the HIV setting in terms of trust, communication, and bonding. Previous studies found a stronger mediation effect of patient trust on patient-centered communication (PCC) as the frequency of patient hospital visits increased (Hong \& Oh, 2020) and a partial mediation effect of patient trust on the relationship between nurses' cultural competence and patient satisfaction (Tang et al., 2019). Patient satisfaction mediates nursing service quality and patient loyalty and between the physical environment, customerfriendly environment, and patient loyalty (Fatima et al., 2018; Schaal et al., 2016). There is, however, scant information on the mediation role of patient-provider attachment and particularly in HIV care.

\section{Methods}

\section{Study design and area}

This study employs a mixed-methods study design. The study will be conducted at Academic Model Providing Access to Healthcare (MTRH-AMPATH) in Eldoret, Kenya. AMPATH is in partnership with MTRH and the College of Health Sciences (MUCHS), Moi University in Eldoret Kenya, and a consortium of North American academic medical centers (Einterz et al., 2007). AMPATH serves a catchment area of 4 million people and has supported HIV care delivery for over 180,000 patients at nearly 150 Ministry of Health (MOH) sites across western Kenya. The AMPATH model leads in promoting and fostering a comprehensive approach to HIV/AIDS control that complements and enhances the available health infrastructure. It provides free antiretroviral therapy (ART) to all patients qualifying for therapy, as well as comprehensive nutrition services, psychosocial support, and economic development training. Importantly, AMPATH collaborates with healthcare providers at all levels of government to community health workers (CHWs) in providing effective care that is culturally sound (Karwa et al., 2017). For this reason, AMPATH forms a healthcare system with all the infrastructural arrangements that provide a basis for studying the healthcare system leadership, patient-provider relational dynamics, and loyalty of patients in HIV care.

\section{Target population}

The study involves adult HIV-infected patients and healthcare providers (clinicians, nurses, social workers, HTCs, nutritionists, and retention workers) in MTRH-AMPATH. This population interacts with patients within the healthcare system environment that are organized into care modules (1-3) for adults; each module is headed by a clinical officer who plays a leadership role. At the end of July 2019, the total population of adult $\mathrm{HIV}$-infected persons (aged $\geq 18$ ) receiving ART medication both in the active and the lost-to-follow-up (LTFU) categories was 26,064 (MTRH-AMPATH records, July 2018) and corresponding 50 healthcare providers (MTRH-AMPATH records, July 2019).

\section{Inclusion and exclusion criteria}

The inclusion criteria are adult HIV-infected patients under the AMPATH care treatment plan, currently on ART in classified care modules (adult modules 1-3), aged 18 years and older, and voluntarily willing to participate in the study. The healthcare providers in the corresponding care modules must also have at least 1 years' experience in HIV care. Patients who present with severe illness or psychological cases will be excluded from the study. Similarly, healthcare providers that have busy schedules at the time of the study will be excluded.

\section{Sampling design, sample size, and procedures}

Sample size. To generate the sample size for the patients, the Yamane (Yamane, 1967) formula below was used to compute the sample size with a relative precision of $\pm 5 \%$ and a $95 \%$ confidence level, where $\mathrm{n}$ is the sample size, $\mathrm{N}$ is the population size and e is the level of precision.

$$
n=\frac{N}{1+N(e)^{2}}
$$

In this formula;

$\mathrm{N}=$ Population size $(26,064)$ of active and LTFU patients in care modules 1-3 are treated as strata

$\mathrm{e}=$ Sampling error $(0.05)$

$\mathrm{n}=$ Sample size (394)

To sample the patient categories from the total sample size $(n=394)$ (Table 1), a proportionate sampling approach is used to categorize patients into adult care (modules 1-3). The sampling approach allows stratification of the active and lost to follow up (LTFU) patients proportionately. To ensure an equal chance of participation from each of the three strata care modules, a fraction of the population from each stratum is multiplied by the total sample to get the respective sample population for each module. This generates (for module $1, \mathrm{n}=128$, module $2, \mathrm{n}=135$ and module $3, \mathrm{n}=131$ ) respectively. From each module, the study sample size $(n=394)$ is divided by the estimated population size to obtain a systematic random starting point. In this case, every $3^{\text {rd }}$ patient will be systematically selected to participate in the study until the desired sample is achieved. Notably, clinicians in each of the adult care modules attend to at least 80 patients per day (MTRH-AMPATH daily clinical records). For the healthcare providers (HCPs), the total population sample is 50 in the HIV facility; a census will be used to enroll all of them from their various departments. They play a critical role in the provision of HIV patient care, interact and build relationships with HIV patients and other providers including their leaders in charge. Based on their HIV care experience, they understand the healthcare system structures and patient-provider relationship dynamics hence will respond to the issues of strategic leadership 


\begin{tabular}{|c|c|c|c|c|}
\hline $\begin{array}{l}\text { MTRH Care } \\
\text { Module }\end{array}$ & & $\begin{array}{l}\text { Total } \\
\text { per } \\
\text { module }\end{array}$ & $\begin{array}{l}\text { Proportionate } \\
\text { Sample } \\
\text { Distribution (x) } \\
=(\mathbf{x}=\mathbf{a} / \mathbf{N} \times \mathbf{n})\end{array}$ & $\begin{array}{l}\text { Systematic } \\
\text { Sampling } \\
\text { (sample size/ } \\
\text { total } \Sigma(\mathbf{x}) \\
=\mathrm{n} / \Sigma(\mathbf{x})\end{array}$ \\
\hline \multicolumn{5}{|l|}{ Module 1} \\
\hline Active & \multicolumn{2}{|l|}{3541} & \multicolumn{2}{|l|}{54} \\
\hline $\begin{array}{l}\text { Lost to follow } \\
\text { up (LTFU) }\end{array}$ & 4873 & 8414 & 74 & \\
\hline \multicolumn{3}{|l|}{ Total } & \multirow[t]{2}{*}{128} & 3.08 \\
\hline \multicolumn{4}{|l|}{ Module 2} & \\
\hline Active & \multicolumn{2}{|l|}{4450} & \multicolumn{2}{|l|}{67} \\
\hline LTFU & 4522 & 8972 & 68 & \\
\hline \multicolumn{3}{|l|}{ Total } & 135 & 2.92 \\
\hline \multicolumn{5}{|l|}{ Module 3} \\
\hline Active & \multicolumn{2}{|l|}{4173} & \multicolumn{2}{|l|}{63} \\
\hline LTFU & 4505 & 8678 & 68 & \\
\hline Total & \multicolumn{2}{|l|}{26064} & 131 & 3.01 \\
\hline
\end{tabular}

Source: MTRH-AMPATH Records, July 2018.

and healthcare provision. For the qualitative methods, purposive and convenient sampling strategies will be used to select 22 healthcare providers to obtain an in-depth understanding of healthcare system leadership until data saturation.

\section{Recruitment of study participants}

Patients will be recruited from two points. First, clinicians will be requested to refer them to a room where this study will be done after examination and be approached at the point of entry (at the triage section). The patient flow in each of the care modules is systematic where patients are first triaged before they see a clinician or directed to the right point of care. The healthcare providers will be approached individually in their respective care modules, requested to fill in a questionnaire and participate in in-depth interviews at a convenient date and time. Those who accept to participate will first consent.

\section{Variable measures}

Patient loyalty (dependent variable). Patient loyalty will be measured using five behavioral items obtained from customer loyalty and patient loyalty measures that had been utilized by previous studies on a 5-point Likert scale ranging from ( $1=$ strongly disagree to $5=$ strongly agree) and showed good reliabilities of $\alpha>0.70$ (Hacettepe et al., 2016; Juhana et al., 2015; Lee, 2019; Ngoma \& Ntale, 2019). Patient loyalty assesses the commitment of the patient to repurchase products and services of an organization repeatedly, feelings toward the hospital, and willingness to recommend the hospital to others (Hacettepe et al., 2016; Juhana et al., 2015; Lee, 2019; Ngoma \& Ntale, 2019). The items will be subjected to principal component analysis (PCA) to extract factors $\geq 5$ through an orthogonal rotation (varimax with Kaiser Normalization) (Chan \& Idris, 2017; Kim et al., 2017), to assess validity. Next, a data transformation procedure will be conducted to determine the means that will be used for multivariate analysis and this process will be applied to all the variables in the study.

Strategic leader attributes. Two dimensions will be used (the adaptive leadership framework and clinical leader attributes). The Adaptive Leadership Framework developed by Heifetz (Heifetz \& Laurie, 1997) for business does not only focus on the leaders' capabilities but also on the leaderfollower relationship as well as internal and external factors that impact the organization. This framework has been applied in the healthcare setting e.g. in chronic illness, (Anderson et al., 2015; Bailey et al., 2019), focusing on the leadership attributes to influence the healthcare system where the adaptive and collaborative work takes place between the patients and the healthcare providers and other stakeholders. Seven items adapted from the framework were modified and simplified to suit the current study. The items use a 5-point Likert scale ranging from ( $1=$ strongly disagree to $5=$ strongly agree). While clinical leader attributes, 10 questions on a 5-point Likert scale ranging from ( $1=$ strongly disagree to $5=$ strongly agree) are a collection of measures from previous studies 
including the clinical leadership competency framework assessment tool (NHS Leadership Academy, 2011), attributes of clinical leadership (Mannix et al., 2013) and Victoria Quality Council. These items have been widely used in other studies in clinical settings and have demonstrated good reliabilities (NHS Leadership Academy, 2011; Nicol, 2012).

Healthcare system factors (mediating variable). Healthcare system factors are measured by the use of non-health aspects of care that relate to the care environment and the way healthcare is offered to clients. The 10 items from the WHO healthcare system framework measuring healthcare system responsiveness and performance will be used. Studies that have utilized these measures borrowed from the WHO health system responsiveness framework and modified to suit the relevant context and asked questions in a 5-point Likert scale (Chao et al., 2017; Miller et al., 2015; Murray \& Frenk, 2000; Rachlis et al., 2016; Rashidian et al., 2011) showed good reliabilities. Like other variables, the items are measured on a 5-point Likert scale ranging from ( $1=$ strongly disagree to $5=$ strongly agree) .

Patient-provider relational dynamics (mediating variable). To measure relational dynamics, patient trust in the healthcare provider and the healthcare system, patient-provider communication, and patient-provider relational bonding/attachment assesses patient-provider relational dynamics. To assess patient trust, 10 items that have been utilized in previous studies will be used. These questions will ask patient trust in the healthcare system to give the possible best care, patient confidence in the healthcare system to provide possible care, trust in the provider to provide accurate medical information, make an excellent medical judgment on behalf of the patient, provide treatment options for the patient, prioritize patient medical needs and worrying less by putting their lives in the hands of the providers. Also, providers caring for their needs than those of the patients and the chances of not keeping patient information private. All questions will be asked on a 5-point Likert scale, ranging from strongly agree to strongly disagree. The measures indicated good reliabilities of >0.85 (Anderson \& Dedrick, 1990; Dugan et al., 2005; Thom et al., 1999).

Patient-provider communication. To measure patient-provider communication, a collection of measures from the perspectives of patient-centered communication, physician communication, and provider-patient communication will be utilized and particularly from the core functions of patient-centered communication. A total of eight questions, including the provider greeting the patients to make them feel comfortable, providing a chance for the patient to ask health-related questions and the provider answering them, involving the patient in decision making concerning their health, spending enough time with the patient in explaining things for better understanding, helping the patients to deal with feelings of doubt by encouraging them to express their thoughts concerning health problems and, checking to see if the patient treatment plan is acceptable. These questions will be asked on a 5-point Likert scale (1=strongly disagree to $5=$ strongly agree) to assess this construct from previous studies that showed acceptable validity and reliability of > 0.80. (Jiang, 2017; Wachira et al., 2014).

Patient-provider bonding/attachment. Attachment theory has been used as a model of doctor-patient interaction framework for clarifying, measuring, and training medical personnel in the advancement of patient-centered care (Cassedy et al., 2015). To measure patient-provider relational bonding/attachment, 10-items from the Relationship Style Questionnaire on a 5-point Likert scale ranging from (1=strongly disagree to $5=$ strongly agree) will be used. The framework has been used to assess diverse healthcare issues that focus on experiences in close relationships. For example, in HIV care, HIV + patients with insecure attachment styles are more likely to experiences higher levels of stress and worse adjustment to illness than those with secure attachment styles (Koopman et al., 2000). This tool was also administered in a low-income country with good reliabilities (Holmes \& Lyons-ruth, 2006).

\section{Reliability and validity}

The reliability of the instrument will be tested using the Cronbach alpha coefficient to assess the internal consistency of the scale (Portillo, 2011). Accordingly, reliability values of greater than 0.70 indicate the data instrument is reliable (Masa'deh et al., 2016). Exploratory factor analysis (EFA) will also be used to assess convergent validity by assessing the factor loadings of items on specific constructs and assess goodness fit of the model in predicting the primary outcome using statistical indices (Masa'deh et al., 2016). Normally, factor loadings of greater than 0.50 indicate a variance in the respective measurement items. The study will also examine the quality of data by testing regression assumptions as a pre-requisite for multivariate data analysis to avert potentially severe effects on the ability to draw inferences from the analysis of data (Ernst \& Albers, 2017). These include normality, linearity, autocorrelation, and multi-collinearity statistical tests. The data instruments will first be pre-tested before data collection by administering the survey questionnaire to ten participants, including six patients and four healthcare providers, to determine the suitability of the questions. Likewise, for the interviewer guide, four healthcare providers stratified by gender will be interviewed. The pre-testing exercise will take approximately an hour in the HIV facility. Any suggestions and amendments arising from the respondents, will be incorporated in the instruments before final administration and the pre-tested data will be excluded in the final data analysis.

\section{Study conceptual framework}

The conceptual framework in this study consists of domains that influence the aspects of patient loyalty to HIV care including strategic clinical leader attributes, healthcare system factors, and patient-provider relational dynamics. The assumption is that a clinical leader in charge who possess strategic attributes can influence the healthcare system environment characterized by complex and dynamic factors, where the patient-provider relational dynamics take place. Both the providers and patients have unique characteristics that enable them to 
engage in relational dynamics which in turn influence patient loyalty to HIV care directly or through mediation. This conceptual framework is supported by the Theory of Planned Behavior (TPB) advanced by Ajzen (1991) and the complexity theory by George A. Cowan, the head of research at the Los Alamos nuclear laboratory in the mid-1980s (Golash-Boza et al., 2012). TPB provides that an individual's behavior is driven by desires or intentions that are motivated by the attitude toward the behavior, subjective norms, and perceived control of behavior (Sniehotta et al, 2014) (Ajzen, 1991), in this case, loyalty to HIV care behavior. In most HIV studies, TPB has been used to predict behaviors such as condom use (Espada et al., 2016; Semungus et al., 2017), HIV testing intention (Ayodele, 2017), intentions to adhere to ART (Saal \& Kagee, 2012). The complexity theory, on the other hand, is described based on the interrelatedness of components of a system on each other where the complexity increases with the number of components and the unique relations between them (Kannampallil et. al., 2011), which may be explained by the interactions of multiple factors within the healthcare system that may influence patient loyalty to HIV care. For example, in leadership studies, complexity theory is used to manage complex situations (Marion, 2008) by utilizing the adaptive leadership framework in implementing culture change in nursing homes, (Corazzini et. al., 2015), adaptive leadership and person-centered care (Corazzini \& Anderson, 2015). While TPB has inspired numerous health research, studies have been criticized for their static explanatory nature, which does not provide a clear understanding of behavioral evidenced effects on participants' cognitions and future behavior (McEachan et al., 2011), while complexity theory assumptions remain murky despite much description, which hinders the development of its implications for leadership (Schneider \& Somers, 2006). In the present study, the theories support the prediction of patient loyalty to HIV care considering the complexities that occur within the healthcare system when different elements interact with each other creating tensions that may hinder patient loyalty to HIV care (Figure 1).

\section{Data analysis and statistical plan}

For quantitative data, data processing and management shall be done which will include developing codes in SPSS for easy data entry, data cleaning, and test for regression assumptions before testing hypotheses. A paired statistic from the patients and healthcare providers will be computed and used to test the hypotheses utilizing the hierarchical regression method for direct effects and Hayes PROCESS Macro Model No.6 (Hayes, 2013) for serial mediations in SPSS vs.23 following the

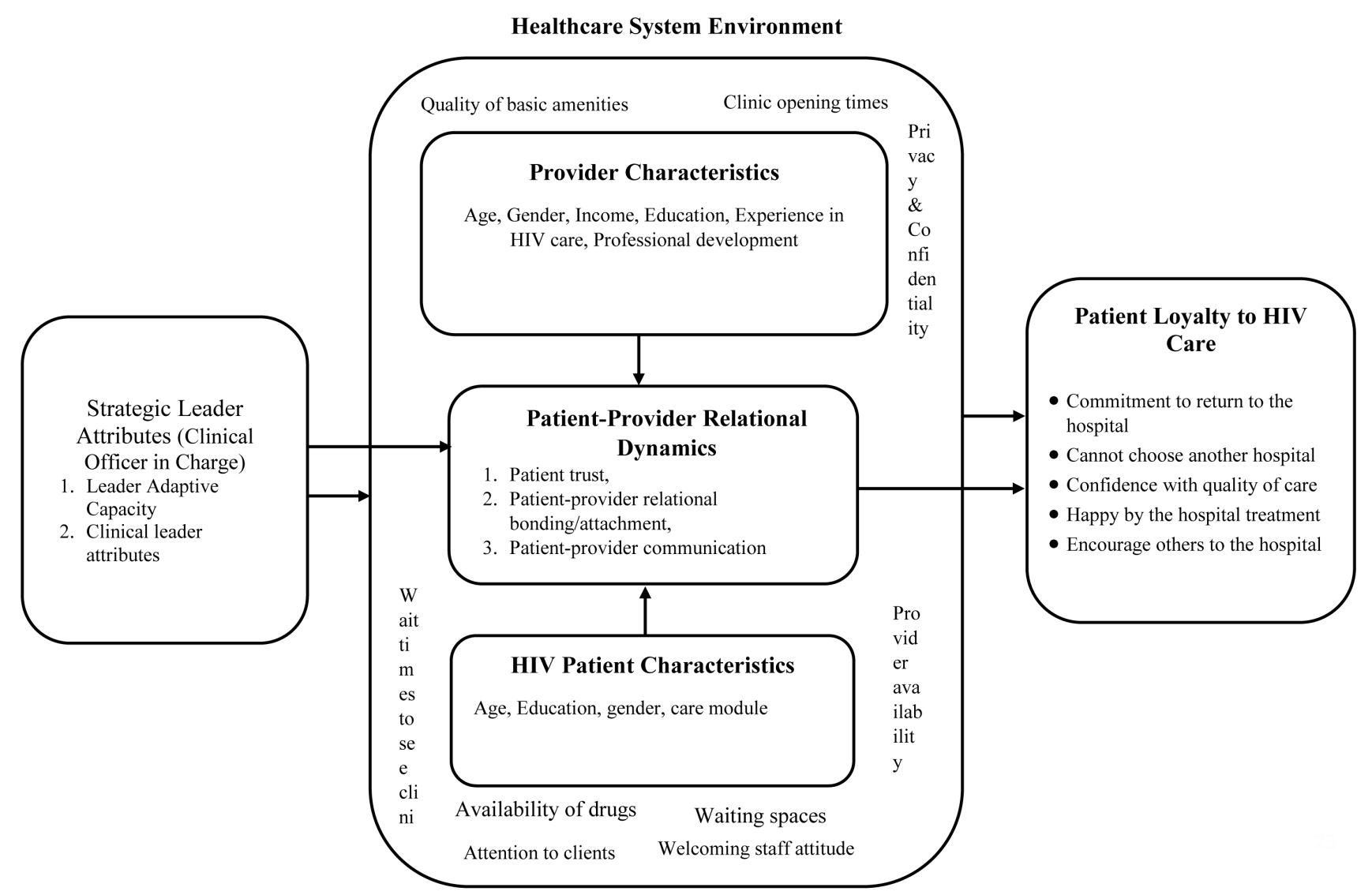

Figure 1. Conceptual Framework. 
conceptual framework (Figure 1). Patient demographic characteristics will be used to adjust for confounding effects. Descriptive statistics will also be analyzed to present participant and variable characteristics respectively. For the qualitative data, audio recorded data will be transcribed, translated and codes developed in N-Vivo software vs.11 then, emerging themes will be identified that will inform thematic analysis of the data. Data will be presented in the form of narratives and the lifting of quotes.

\section{Ethical considerations}

This study has received ethical approval from the Institutional Research Ethics Committee (IREC) in Moi Teaching and Referral Hospital (MTRH) (Approval No.0003485), a permit letter from the MTRH-AMPATH HIV facility and, a research license from the National Commission for Science, Technology, and Innovation (NACOSTI No NACOSTI/ $\mathrm{P} / 20 / 3253$ ), to collect data from the adult HIV-infected patients and the health care providers in MTRH-AMPATH HIV facility. Before signing informed consent, participants will be given sufficient information explaining the study purpose and procedures. Participants who do not understand English will be explained in Swahili. To ensure the privacy and confidentiality of the participants, a private room within the HIV facility will be identified for collecting data. Also, participant data shall be kept confidential by only using it for the study and de-identifying data that may link the participants to protect anonymity. Overall, participants will be treated equally and fairly during enrollment and participation.

\section{Dissemination of study outcomes}

Study findings will be shared with the Moi Teaching and Referral Hospital, HIV facility leaders, the study participants, in the Moi University Library as a thesis document for future knowledge sharing, in refereed journals and book chapters.

\section{Conclusions}

Patient loyalty is well researched in areas of marketing and healthcare studies in examining patient outcomes such as safety and mortality. This study provides an opportunity to extend investigations beyond the patient loyalty antecedents to determine how multiple factors such as strategic clinical leadership within a healthcare system, factors surrounding the care system and patient-provider relational dynamics influence patient loyalty to HIV care in an HIV facility in Eldoret, Kenya directly or indirectly through mediations utilizing statistical models to test interactions and relationships among the variables.

\section{Data availability}

No data are associated with this article.

\section{Author contributions}

FA: Conceptualization, methodology, writing the original draft, review, and edit

JW, MK \& VB: Conceptualization, methodology, supervision, review, and edit of the final draft

\section{References}

Adhi Mahendrayana Putu IM, Suyatna N, Putu Indiani YL: The effect of service quality on patient loyalty mediated by patient satisfaction in Bali Siloam Hospital. JAGADHITA. 2018; 5(1): 1-7. Reference Source

Agyei PM, Kilika JM, Mensah PA: Relationship between Corporate Image and Customer Loyalty in the Mobile Telecommunication Market in Kenya. Management Studies. 2014: 2(5): 299-308.

Reference Source

Ajzen I: The Theory of Planned Behavior. Organ Behav Hum Decis Process. 1991; 50(2): 179-211.

Publisher Full Text

Alipoor H, Ahmadi K, Pouya S, et al.: The Effect of Organizational Structure on Employees' Job Performance in Private Hospitals of Ahvaz. Teh Academy of Environmental Biology, India. 2017; 17(3-4): 136-140. Reference Source

Alotaibi EA, ZienYusoff R, Al-Swidi AK, et al.: The Mediating Effect of Organizational Climate on the Relationship between Transformational Leadership and Patient Safety: A Study on Saudi Hospitals. Mediterr J Soc Sci. 2015; 6(2): 117-126.

Publisher Full Text

Amankwah O, Weng-Wai C, Mohammed AH: Modelling the Mediating Effect of Health Care Healing Environment on Core Health Care Delivery and Patient Satisfaction in Ghana. Environ Health Insights. 2019; 13: 117863021985211

PubMed Abstract | Publisher Full Text | Free Full Text

Anderson RA, Bailey DE, Wu B, et al.: Adaptive leadership framework for chronic illness: framing a research agenda for transforming care delivery. ANS Adv Nurs Sci. 2015; 38(2): 83-95.

PubMed Abstract | Publisher Full Text | Free Full Text

Anderson LA, Dedrick RF: Development of the Trust in Physician Scale: A Measure to Assess Interpersonal Trust in Patient-Physician Relationships.
Psychological Reports. 1990; 67(3 Pt 2): 1091-1100

PubMed Abstract | Publisher Full Text

Ayodele O: The Theory of Planned Behavior as a Predictor of HIV Testing Intention. Am J Health Behav. 2017; 41(2): 147-151.

PubMed Abstract | Publisher Full Text

Bailey DE Jr, Docherty SL, Adams JA, et al.: Studying the clinical encounter with the Adaptive Leadership framework. J Healthc Leadersh. 2012; 2012(4): 83-91.

PubMed Abstract | Publisher Full Text | Free Full Text

Bailey DE Jr, Muir AJ, Adams JA, et al.: Clinical Encounters and Treatment Initiation for Chronic Hepatitis C Patients: Applications of Adaptive Leadership Framework for Chronic Illness. Sage Open. 2019; 9(1): 1-11. PubMed Abstract | Publisher Full Text | Free Full Text

Bucciardini R, Fragola V, Abegaz T, et al.: Retention in Care of Adult HIV Patients Initiating Antiretroviral Therapy in Tigray, Ethiopia: A Prospective Observational Cohort Study. PLoS One. 2015; 10(9): e0136117. PubMed Abstract | Publisher Full Text | Free Full Text Cassedy HF, Enander RA, Robinson RC, et al.: Attachment Theory as a Model of Doctor-Patient Interaction. J App/ Biobehav Res. 2015; 20(4): 151-178. Publisher Full Text

Chan LL, Idris N: Validity and Reliability of The Instrument Using Exploratory Factor Analysis and Cronbach's alpha. International Journal of Academic Research in Business and Social Sciences. 2017; 7(10): 400-410. Publisher Full Text

Chao J, Lu B, Zhang $\mathrm{H}$, et al.: Healthcare system responsiveness in Jiangsu Province, China. BMC Health Serv Res. 2017; 17(1): 31. PubMed Abstract | Publisher Full Text | Free Full Text

Corazzini KN, Anderson RA: Adaptive leadership and person-centered care: a new approach to solving problems. N C Med J. 2015; 75(5): 352-354. PubMed Abstract | Publisher Full Text

Corazzini K, Twersky J, White HK, et al.: Implementing culture change in 
nursing homes: An adaptive leadership framework. Gerontologist. 2015; 55(4): 616-627.

PubMed Abstract | Publisher Full Text | Free Full Text

Daly J, Jackson D, Mannix J, et al.: The importance of clinical leadership in the hospital setting. J Healthc Leadersh. 2014; 6: 75-83.

Publisher Full Text

Dugan E, Trachtenberg F, Hall MA: Development of abbreviated measures to assess patient trust in a physician, a health insurer, and the medical profession. BMC Health Serv Res. 2005; 5: 64.

PubMed Abstract | Publisher Full Text | Free Full Text

Edmonstone J: The development of strategic clinical leaders in the National Health Service in Scotland. Leadership in Health Services. 2011; 24(4): 337-353. Publisher Full Text

Einterz RM, Kimaiyo S, Mengech HNK, et al.: Responding to the HIV pandemic: The power of an academic medical partnership. Acad Med. Lippincott Williams and Wilkins. 2007; 82(8): 812-8.

PubMed Abstract | Publisher Full Text

Ernst AF, Albers Cj: Regression assumptions in clinical psychology research practice - a systematic review of common misconceptions. PeerJ. 2017; 5: e3323.

PubMed Abstract | Publisher Full Text | Free Full Text

Espada JP, Morales A, Guillén-riquelme A, et al.: Predicting condom use in adolescents: a test of three socio-cognitive models using a structural equation modeling approach. BMC Public Health. 2016; 16: 35.

PubMed Abstract | Publisher Full Text | Free Full Text

Fatima T, Malik SA, Shabbir A: Hospital healthcare service quality, patient satisfaction and loyalty: An investigation in context of private healthcare systems. International Journal of Quality and Reliability Management. 2018; 35(6): 1195-1214.

Publisher Full Text

Genberg B, Wachira J, Kafu C, et al.: Health System Factors Constrain HIV Care Providers in Delivering High-Quality Care: Perceptions from a Qualitative Study of Providers in Western Kenya. J Int Assoc Provid AIDS Care. 2019; 18: 2325958218823285.

PubMed Abstract | Publisher Full Text | Free Full Text

Gilson L, Agyepong IA: Strengthening health system leadership for better governance: what does it take? Health Policy Plan. 2018; 33(suppl_2): ii1-ii4. PubMed Abstract | Publisher Full Text | Free Full Text

Gilson L, Daire J: Leadership and Governance within the South African Health System. In SAHR. 2011; 69-80.

Reference Source

Golash-Boza T, Moreira I, de C, et al:: Complexity and the Adoption of Innovation. BMJ (Clinical Research Ed.). 2012; 1(1): 163-181.

Govender S, Proches CNG, Kader A: Examining leadership as a strategy to enhance health care service delivery in regional hospitals in South Africa. J Multidiscip Healthc. 2018; 11: 157-166.

PubMed Abstract | Publisher Full Text | Free Full Text

Hacettepe LO, Basgoze P, Pamukkale AK: The association between perceived value and patient loyalty in public university hospitals in Turkey. Total Qual Manag Bus. 2016; 28(7-8): 782-800.

Publisher Full Tex

Hamood A, Alshehari A: The Mediating Role of Hospital Environment in The Relationship Between Service Quality And Customers Loyalty. Arraskhun International Journal. 2018; 4(2): 2462-2508.

Reference Source

Hayes AF: Introduction to Mediation, Moderation, and Conditional Process Analysis. 2013.

Heifetz RA, Grashow A, Linsky M: The practice of adaptive leadership: Tools and tacits for changing your organization and the world. 2009.

Reference Source

Heifetz R, Laurie D: the_Work_of_Leadership_Ronald_a_Heifetz_and_Donald L Lauri. Harvard Business Review. 1997.

Higgins EA: The Influence of Nurse Manager Transformational Leadership on Nurse and Patient Outcomes: Mediating Effects of Supportive Practice Environments, Organizational Citizenship Behaviours, Patient Safety Culture and Nurse Job Satisfaction. 2015.

Reference Source

Holmes BM, Lyons-Ruth K: The relationship questionnaire-clinical version (RQ-CV): Introducing a profoundly-distrustful attachment style. Infant Men Health J. 2006; 27(3): 310-325.

PubMed Abstract | Publisher Full Text | Free Full Text

Hong $\mathrm{H}, \mathrm{Oh} \mathrm{HJ}$ : The Effects of Patient-Centered Communication: Exploring the Mediating Role of Trust in Healthcare Providers. Health Commun. 2020; 35(4): 502-511.

PubMed Abstract | Publisher Full Text

Jiang S: Pathway Linking Patient-Centered Communication to Emotiona Well-Being: Taking into Account Patient Satisfaction and Emotion Management. J Health Commun. 2017; 22(3): 234-242.

PubMed Abstract | Publisher Full Text

Juhana D, Manik E, Febrinella C, et al.: Empirical study on patient satisfaction and patient loyalty on public hospital in Bandung, Indonesia. International Journal of Applied Business and Economic Research. 2015; 13(6): 4305-4326. Reference Source
Kannampallil TG, Schauer GF, Cohen T, et al.: Considering complexity in healthcare systems. J Biomed Inform. 2011; 44(6): 943-947.

PubMed Abstract | Publisher Full Text

Karwa R, Maina M, Mercer T, et al.: Leveraging peer-based support to facilitate HIV care in Kenya. PLoS Med. 2017; 14(7): e1002355.

PubMed Abstract | Publisher Full Text | Free Full Text

Kawonga $M$, Blaauw $D$, Fonn $S$ : The influence of health system

organizational structure and culture on integration of health services: the example of HIV service monitoring in South Africa. Health Policy Plan. 2016; 31(9): $1270-1280$

PubMed Abstract | Publisher Full Tex

Kilowua LM, Otieno KO: Health System Factors Affecting Uptake of Antenatal Care by Women of Reproductive Age in Kisumu County, Kenya. International Journal of Public Health and Epidemiology Research. 2019; 5(2): $119-124$

Reference Source

Kim CE, Shin JS, Lee J, et al.: Quality of medical service, patient satisfaction and loyalty with a focus on interpersonal-based medical service encounters and treatment effectiveness: a cross-sectional multicenter study of complementary and alternative medicine (CAM) hospitals. BMC Complement Altern Med. 2017; 17(1): 174

PubMed Abstract | Publisher Full Text | Free Full Text

Kipkirong Tarus D, Rabach N: Determinants of customer loyalty in Kenya: does corporate image play a moderating role? The TQM Journal. 2013; 25(5): 473-491.

Publisher Full Text

Kiplagat J, Mwangi A, Keter A, et al.: Retention in care among older adults living with HIV in western Kenya: A retrospective observational cohort study. PLoS One. 2018; 13(3): e0194047.

PubMed Abstract | Publisher Full Text | Free Full Text

Koopman C, Gore-Felton C, Marouf F, et al.: Relationships of perceived stress to coping, attachment and social support among HIV-positive persons. AIDS Care. 2000; 12(5): 663-672.

PubMed Abstract | Publisher Full Text

Larsson IE, Sahlsten MJM: The Staff Nurse Clinical Leader at the Bedside:

Swedish Registered Nurses' Perceptions. Nurs Res Pract. 2016; 2016:

1797014-8.

PubMed Abstract | Publisher Full Text | Free Full Text

Lee C: Does Corporate Social Responsibility Influence Customer Loyalty in the Taiwan Insurance Sector? The role of Corporate Image and Customer Satisfaction. Journal of Promotion Management. 2019; 25(1): 43-64. Publisher Full Text

Mannix J, Wilkes L, Daly J: Attributes of clinical leadership in contemporary nursing: an integrative review. Contemp Nurse. 2013; 45(1): 10-21.

PubMed Abstract | Publisher Full Text

Marion R: Complexity Leadership: Part 1: Conceptual Foundations - Google Books. 2008.

Reference Source

Masa'deh R, Obeidat BY, Tarhini A: A Jordanian empirical study of the associations among transformational leadership, transactional leadership knowledge sharing, job performance, and firm performance: A structura equation modelling approach. Journal of Management Development. 2016; 35(5): 681-705

Publisher Full Text

McCollum R, Limato R, Otiso L, et al.: Health system governance following devolution: comparing experiences of decentralisation in Kenya and

Indonesia. BMJ Global Health. 2018; 3(5): e000939.

PubMed Abstract | Publisher Full Text | Free Full Text

McEachan RRC, Conner M, Taylor NJ, et al.: Prospective prediction of healthrelated behaviours with the Theory of Planned Behaviour: a meta-analysis. Health Psychol Rev. 2011; 5(2): 97-144.

Publisher Full Text

Miller JS, Mhalu A, Chalamilla G, et al.: Patient satisfaction with HIV/AIDS care at private clinics in Dar es Salaam, Tanzania. AIDS Care. 2015; 26(9): $1150-1154$

PubMed Abstract | Publisher Full Text | Free Full Text

Mortazavi S, Kazemi M, Shirazi A, et al.: The Relationships between Patient Satisfaction and Loyalty in The Private Hospital Industry. Iranian J Publ Health. 2009; 38(3): 60-69.

Reference Source

Mulaki A, Muchiria S: Kenya Health System Assessment. 2019.

Reference Source

Murray CJL, Frenk J: A framework for assessing the performance of health systems. Bull World Health Organ. 2000; 78(6): 717-731.

PubMed Abstract | Free Full Text

Mwamba C, Sharma A, Mukamba N, et al.: 'They care rudely!': Resourcing and relational health system factors that influence retention in care for people living with HIV in Zambia. BMJ Global Health. 2018; 3(5): e001007. PubMed Abstract | Publisher Full Text | Free Full Text

Ngoma M, Ntale PD: Word of mouth communication: A mediator of relationship marketing and customer loyalty. Cogent Business \& Management 2019; 6(1): 1-20.

Publisher Full Text 
Ngurah IM, Mahardika O, Suardhika IN, et al.: Determination Loyalty Based on Service Quality, Customer Satisfaction and Trust at Pt. Bpr Bukit Tanjung Badung. International Journal of Contemporary Research and Review. 2018; 9(2): 20473-20484.

Publisher Full Text

NHS Leadership Academy: Clinical Leadership Competency Framework. Self assessment tool. Innovation. 2011.

Reference Source

Nicol: Improving clinical leadership and management in the NHS. J Healthc Leadersh. 2012; 4: 59-69.

Publisher Full Text

Nzinga J, McGivern G, English, M: Examining clinical leadership in Kenyan public hospitals through the distributed leadership lens. Health Policy Plan 2018; 33(Suupl.2): ii27-ii34.

PubMed Abstract | Publisher Full Text | Free Full Text

Portillo DMC: Relationship between organizational culture, leadership behavior and job satisfaction. BMC Health Serv Res. 2011; 11: 98.

PubMed Abstract | Publisher Full Text | Free Full Text

Rachlis B, Bakoyannis G, Easterbrook P, et al.: Facility-Level Factors Influencing Retention of Patients in HIV Care in East Africa. PloS One. 2016; 11(8): e0159994.

PubMed Abstract | Publisher Full Text | Free Full Text

Rashidian A, Kavosi Z, Majdzadeh, R, et al.: Assessing Health System Responsiveness: A Household Survey in 17th District of Tehran. Iran Red Crescent Med J. 2011; 13(5): 302-308.

PubMed Abstract | Free Full Text

Roberge D, Beaulieu MD, Haddad, S, et al.: Loyalty to the regular care provider: patients' and physicians' views. Family Practice. 2001; 18(1): 53-59.

Publisher Full Text

Saal W, Kagee A: The applicability of the Theory of Planned Behaviour in predicting adherence to ART among a South African sample.J Health Psychol. 2012; 17(3): 362-370.

PubMed Abstract | Publisher Full Text

Schaal T, Schoenfelder T, Klewer J, et al.: Determinants of patient satisfaction and their willingness to return after primary total hip replacement : a cross-sectional study. BMC Musculoskelet Disord. 2016; 17(330): 1-9. PubMed Abstract | Publisher Full Text | Free Full Text

Schneider M, Somers M: Organizations as complex adaptive systems: Implications of Complexity Theory for leadership research. Leadersh $Q$ 2006; 17(4): 351-365.

Publisher Full Text

Semungus A, Tafese Z, Semella T: Application of the Theory of Planned Behavior to Assess the Determinants of HIV/AIDS Risk among High Schoo
Students in Hawassa City, Ethiopia. J Community Public Health Nurs. 2017; 3(1): Publisher Full Text

Sexton A, Sen D: More voice, less ventriloquism- exploring the relationa dynamics in a participatory archive of mental health recovery. International Journal of Heritage Studies. 2018; 24(8): 874-888.

Publisher Full Text

Sniehotta FF, Presseau J, Araújo-Soares V: Time to retire the theory of planned behaviour. Health Psychol Rev. 2014; 8(1): 1-7.

PubMed Abstract | Publisher Full Text

Stevenson EL, Mceleny KR, Moody E, et al.: Applying the Adaptive Leadership Framework for Chronic Illness to understand how American and British men navigate the infertility process. Health Psychology Open. 2019; 6(2): 2055102919871647

PubMed Abstract | Publisher Full Text | Free Full Text

Tang C, Tian B, Zhang X, et al.: The influence of cultural competence of nurses on patient satisfaction and the mediating effect of patient trust. J Adv Nurs. 2019; 75(4): 749-759.

PubMed Abstract | Publisher Full Tex

Thom DH, Ribisl KM, Stewart AL, et al.: Further validation and reliability testing of the Trust in Physician Scale. The Stanford Trust Study Physicians. Med Care. 1999; 37(5): 510-517.

PubMed Abstract | Publisher Full Tex

van der Kop ML, Nagide PI, Thabane L, et al.: Retention in clinic versus retention in care during the first year of HIV care in Nairobi, Kenya: a prospective cohort study. J Int AIDS Soc. 2018; 21(11): e25196.

PubMed Abstract | Publisher Full Text | Free Full Text

Wachira J, Genberg B, Kafu C, et al.: The Perspective of HIV Providers in Western Kenya on Provider-Patient Relationships. J Health Commun. 2018; 23(6): 591-596.

PubMed Abstract | Publisher Full Text | Free Full Text

Wachira J, Middlestadt S, Reece M, et al.: Physician communication behaviors from the perspective of adult HIV patients in Kenya. Int J Qual Health Care. 2014; 26(2): 190-197.

PubMed Abstract | Publisher Full Text

Waibel S, Vargas I, Coderch J, et al.: Relational continuity with primary and secondary care doctors: A qualitative study of perceptions of users of the Catalan national health system. BMC Health Serv Res. 2018; 18(1): 257. PubMed Abstract | Publisher Full Text | Free Full Text

Yamane T: Statistics, An Introductory Analysis. 1967; 2. Reference Source

Zhou WJ, Wan QQ, Liu CY, et al.: Determinants of patient loyalty to healthcare providers: An integrative review. Int J Qual Health Care. 2017; 29(4): 442-449.

PubMed Abstract | Publisher Full Text 


\section{Open Peer Review}

\section{Current Peer Review Status: ? ?}

\section{Version 1}

Reviewer Report 05 January 2021

https://doi.org/10.21956/aasopenres.14221.r28051

(C) 2021 Protière $\mathbf{C}$. This is an open access peer review report distributed under the terms of the Creative Commons Attribution License, which permits unrestricted use, distribution, and reproduction in any medium, provided the original work is properly cited.

\section{Christel Protière}

INSERM, IRD, SESSTIM, Sciences Economiques \& Sociales de la Santé \& Traitement de I'Information Médicale, Aix Marseille University, Marseille, France

It should be interesting to discuss similarities and distinctions between the concept of loyalty and others like adherence, patients empowerment or patient-physicians relationships. At least the authors should better define the way they considered patients' loyalty (toward care, toward physicians or toward the hospital?).

Perhaps some "old" references about the patient-physicians relationships might help (Gafni et al. for example that defined the different models of patients-physicians relationships)

The objectives of the study protocol have to be clearly defined.

Using qualitative and quantitative data is not enough to define a mixed method. It should be interesting to know how they will be interconnected. Additionally, the general themes of the interviews have to be defined.

- If it is clear that health care providers will fill in a questionnaire and will participate in an individual interviews, it is not so clear for the patients. If ever it was not planned, I strongly recommend considering to conduct individual interviews with patients to explore their expectations.

It would be easier to understand the objectives if the conceptual framework was presented earlier in the document.

Regarding the exclusion criteria for healthcare providers, excluding the ones who have busy schedules may introduce a bias (they probably will all have busy schedules, then the assumption could be that only interested ones rather than less busy will participate).

Is the rationale for, and objectives of, the study clearly described? 
Partly

Is the study design appropriate for the research question?

Partly

Are sufficient details of the methods provided to allow replication by others?

Partly

Are the datasets clearly presented in a useable and accessible format?

Not applicable

Competing Interests: No competing interests were disclosed.

Reviewer Expertise: I'm a social scientist (economist and psychologist) working in the field of HIV

I confirm that I have read this submission and believe that I have an appropriate level of expertise to confirm that it is of an acceptable scientific standard, however I have significant reservations, as outlined above.

Author Response 11 Oct 2022

Felishana Cherop, Moi University, Eldoret, Kenya

Dear reviewer, The literature review has been updated to discuss patient loyalty and patient-provider relationships from diverse backgrounds such as marketing, business, HIV, and other healthcare domains. The study focuses on loyalty to the provider and the health system. The objectives have also been clearly deffined and included. However, patients have not been considered in in-depth interviews but we will make recommendations to be included in future studies. The conceptual framework has been shifted to the literature review section after the empirical discussion and the exclusion criteria exclude providers who are not interested to participate in the study. Thank you.

Competing Interests: No competing interests were disclosed.

Reviewer Report 02 December 2020

https://doi.org/10.21956/aasopenres.14221.r28189

(c) 2020 Ahmed S. This is an open access peer review report distributed under the terms of the Creative Commons Attribution License, which permits unrestricted use, distribution, and reproduction in any medium, provided the original work is properly cited.

\section{Selim Ahmed}

World School of Business, World University of Bangladesh, Dhaka, Bangladesh

The authors need to revise the paper according to the following comments: 
1. The authors need to include the literature review as a separate section. Under the literature review the individual research variables and their relationships with empirical evidences must be defined.

2. The study proposed to use two units of data set to test the research model but the question is that how interview data (qualitative) will be used in the model along with survey data (quantitative). Another issue is that 22 responses (healthcare service providers) are proposed for the health service providers which is not acceptable in the statistical analysis.

3. The authors need to discuss practical implications as a separate section.

Is the rationale for, and objectives of, the study clearly described?

Yes

Is the study design appropriate for the research question?

No

Are sufficient details of the methods provided to allow replication by others? Yes

Are the datasets clearly presented in a useable and accessible format?

Not applicable

Competing Interests: No competing interests were disclosed.

Reviewer Expertise: Healthcare Management

I confirm that I have read this submission and believe that I have an appropriate level of expertise to confirm that it is of an acceptable scientific standard, however I have significant reservations, as outlined above.

Author Response 11 Oct 2022

Felishana Cherop, Moi University, Eldoret, Kenya

Dear reviewer, The literature review of the study has been included and the variables indicating the relationships discussed. Qualitative data will be obtained separately from the providers to gain an in-depth understanding of strategic leader attributes for clinical leaders in an HIV health system, hence the data will be analyzed separately and results reported independently. The practical implications of the study have been discusseed and included in the article as a separate section. Thank you.

Competing Interests: No competing interests were disclosed. 